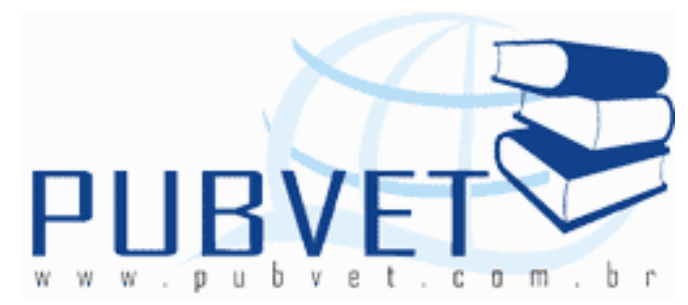

PUBVET, Publicações em Medicina Veterinária e Zootecnia.

Disponível em: <https://doi.org/10.31533/pubvet.v02n11a454>.

\title{
Efeito do protocolo de sincronização de ovulação com Norgestomet e Benzoato de estradiol sobre a citologia vaginal de novilhas e vacas Nelore
}

Henrique Trevizoli Ferraz ${ }^{1}$, Benedito Dias de Oliveira Filho², Maria Lúcia Gambarini², Marco Antônio de Oliveira Viu ${ }^{1}$, Dyomar Toledo Lopes ${ }^{3}$, Luciano Souza Caixeta ${ }^{4}$

${ }^{1}$ Professor do Curso de Medicina Veterinária - UFG/Jataí.

2 Professor(a) da Escola de Veterinária - UFG/Goiânia

3 Doutorando em Ciência Animal - EV/UFG. Bolsista CAPES

${ }^{4}$ Médico Veterinário - Autônomo

\section{RESUMO}

Este estudo objetivou caracterizar o efeito do protocolo hormonal para sincronização da ovulação com progestágeno e benzoato de estradiol (BE) sobre as alterações citológicas vaginais de novilhas e vacas Nelore. Cinco fêmeas de cada categoria receberam implante auricular de norgestomet (NOR) e uma aplicação intra-muscular (IM) de $2,0 \mathrm{mg}$ de $B E$, no dia 0 (D0). No dia 8 (D8), removeu-se os implantes e aplicou-se $0,50 \mathrm{mg}$ de cloprostenol sódico, IM. No dia 9 (D9), aplicou-se 1,0 mg de BE, IM. Durante o protocolo foram coletadas amostras citológicas da mucosa vaginal com o auxílio de escovas 
ginecológicas e os esfregaços corados pelo método panótico. As células parabasais predominaram durante todo o período observado em ambas as categorias. As células intermediárias jovens e as superficiais anucleadas foram mais freqüentemente observadas $(P<0,05)$ após as aplicações de $B E$. Portanto, a citologia vaginal apontou que nas duas categorias de fêmeas Nelore estudadas houve maior número de células basais, intermediárias jovens e superficiais anucleadas depois da aplicação de $B E$, no início do protocolo e predominância de células parabasais durante a permanência do implante de NOR, sob ação progesterônica. A citologia vaginal não forneceu elementos para determinação do momento da ovulação em fêmeas bovinas da raça Nelore submetidas à sincronização da ovulação.

PALAVRAS-CHAVE: bovinos; esfregaço vaginal; IATF; reprodução

\section{Effect of ovulation synchronization protocol with Norgestomet and Estradiol benzoate on vaginal cytology of Nellore heifers and cows}

\section{ABSTRACT}

This study it objectified to characterize the effect of the hormonal protocol for ovulation synchronization with progestagen and estradiol benzoate (BE) on the vaginal cytological alterations of heifers and Nelore cows. Five females of each category had received auricular norgestomet (NOR) implant and a intramuscular application (IM) of 2,0 mg of BE's, in day 0 (D0). In day 8 (D8), one removed the implant and one applied to $0,50 \mathrm{mg}$ of sodic cloprostenol, IM. In D9 it applied 1,0 mg of BE's. Samples of vaginal cytology were daily taken and cellular content stained by panotic method. The parabasal cells predominated during the whole period observed in both the categories. The young intermediary and the anuclear superficial cells were more frequently observed $(P<0,05)$ after BE's applications. Therefore, the vaginal cytology pointed that in the two categories of studied Nelore females it had greater basal cells 
number, anuclear superficial cells and young intermediary cells after BE's applications, the beginning of the protocol and predominance of parabasal cells during the permanence of the NOR implant, on progesterone action. Vaginal cytology didn't give elements to determine the time of ovulation in bovine females of Nelore breed submitted to ovulation synchronization.

KEYWORDS: bovine; reproduction; TAI; vaginal smears

\section{INTRODUÇÃO}

As mudanças citológicas vaginais podem representar um indicador sensível da fase do ciclo estral em várias espécies e reflete, provavelmente, a influência do estrógeno (E2) e da progesterona (P4) (PAPANICOLAOU, 1946). Segundo BANKS (1991) a citologia vaginal estuda as células individualmente, requerendo células esfoliadas, sem considerar a arquitetura do tecido ou órgão de origem, que proporciona um meio simples e rápido de diagnóstico das fases do ciclo estral, sendo um recurso pouco invasivo e de baixo custo.

O diagnóstico das fases do ciclo estral pela citologia vaginal em cadelas é um método confiável para estimar o momento da ovulação (BOUCHARD et al., 1991). Em algumas espécies como cães, gatos, ratos, camundongos e coelhos, as alterações do ciclo estral são bem definidas no aspecto citológico (MIROUD e NOAKES, 1990). HAMILTON e HARRISON (1951) relataram que as mudanças na citologia do trato genital de cabras foram menos evidentes do que em carnívoros e roedores, apesar do seu perfil citológico bem definido. MIROUD e NOAKES (1990) observaram que, em bovinos, as alterações na citologia vaginal durante o ciclo estral não são consistentes. Já KURADE et al. (1993) afirmaram que a citologia vaginal pode ser utilizada como ferramenta para diagnosticar as diferentes fases do ciclo reprodutivo de fêmeas bovinas.

Segundo GOMPEL e KOSS (1997), o epitélio vaginal é provido de receptores hormonais, localizados no núcleo das células, que controlam a maturação e a diferenciação celular. MONTALBÁN (1985) sugere que o E2 
induz a atividade mitótica, estimulando o aumento no número de camadas celulares da vagina. A P4, por sua vez, provoca a diminuição no número de mitoses e a maturação funcional do epitélio (GOMPEL e KOSS, 1997). Adicionalmente, RAMOS et al. (2002) relataram variação na expressão de receptores de E2 e P4 na mucosa cervical de ratos em diferentes fases do ciclo estral, assim como populações celulares características de cada uma destas fases na referida espécie.

Sugere-se que dados mais precisos sobre a colpocitologia característica de cada etapa de um protocolo de sincronização da ovulação (PSO) poderiam auxiliar na determinação da ovulação e, assim, do melhor momento para a realização da inseminação artificial em tempo fixo (IATF). Por isso, desenvolveu-se este trabalho com o objetivo de caracterizar as alterações na citologia vaginal de novilhas e vacas Nelore submetidas a um PSO com a utilização de NOR, BE e cloprostenol sódico.

\section{MATERIAL E MÉTODOS}

Este estudo foi desenvolvido durante o mês de abril de 2006, numa propriedade localizada no município de Caçu, sudoeste do Estado de Goiás. Foram utilizadas cinco novilhas com peso mínimo de $300 \mathrm{~kg}$ e idade entre 24 e 30 meses, e cinco vacas entre a segunda e a quarta ordem de parição com, pelo menos, 60 dias pós-parto. Todos os animais foram submetidos ao seguinte PSO: aplicação, via intramuscular (IM), de 2,0 mg de BE no momento da implantação auricular do NOR, sendo este considerado o dia zero (D0) do protocolo. Após oito dias (D8), juntamente com a retirada do implante, realizou-se a aplicação, IM, de 0,50 mg de cloprostenol sódico. Transcorridas 24 horas, (D9) aplicou-se 1,0 mg de BE, IM.

A atividade ovariana foi acompanhada por meio de exames ultrasonográficos em intervalos de seis horas após a aplicação da segunda dose de $\mathrm{BE}$, até que se verificasse a ovulação do folículo dominante (FD). O momento da ovulação foi estimado pelo intervalo médio entre a observação do maior 
diâmetro do FD e seu desaparecimento na imagem ultra-sonográfica do exame seguinte. Estas avaliações foram feitas com auxílio do aparelho Pie Medical $480^{\circledR}$, equipado com transdutor retal bifreqüencial de $5,0 / 7,5 \mathrm{MHz}$.

O material celular vaginal foi colhido uma vez ao dia, no momento da realização do primeiro exame ultra-sonográfico. Após a higienização da região perivulvar, o espéculo vaginal foi introduzido. Com o auxílio de uma zaragatoa descartável de algodão realizava-se a colheita do material da mucosa vaginal. A zaragatoa foi introduzida na luz do espéculo e colocada em contato com a mucosa da parede superior da vagina, realizando-se então movimentos rotatórios. O material colhido foi depositado em lâminas de vidro e, posteriormente, corado pelo método panótico. A leitura das lâminas foi realizada em microscópio óptico, de forma coordenada em "zig-zag", em aumento de 400 vezes, para a caracterização morfológica e tintorial das células de descamação do epitélio vaginal. O padrão de leitura foi caracterizado pela contagem de 100 células por lâmina. As células esfoliativas foram classificadas segundo MARCONDES (1975) e MIROUD e NOAKES (1990) em basais, parabasais, intermediárias jovens, intermediárias velhas, superficiais nucleadas e superficiais anucleadas. Para permitir a análise das alterações citológicas vaginais durante o PSO, este foi dividido em quatro períodos de três dias cada: Período 1 - do D0 ao D2; Período 2 - do D3 ao D5; Período 3 - do D6 ao D8; e Período 4 - do D9 ao D11.

As variáveis foram analisadas usando os procedimentos do Statistical Analysis System v. 8.0 (SAS, 2000), sendo que, primeiramente, realizou-se análises de crítica e consistência (freqüências, distribuições de freqüências e homogeneidade de variâncias) usando-se o procedimento Univariate. Procedeu-se então a análise de variância, através do General Linear Models, cujo modelo matemático continha como efeito fixo somente o período do protocolo. 


\section{RESULTADOS E DISCUSSÃO}

As porcentagens médias dos tipos celulares vaginais encontrados nos quatro períodos do protocolo hormonal em novilhas e vacas podem ser visualizadas nas TABELAS 1 e 2 . As células basais foram encontradas com maior freqüência $(P<0,05)$ no primeiro período do PSO nas novilhas e nas vacas. A maior concentração deste tipo celular no início do protocolo (D0), deve-se à variação no estágio do ciclo estral dos animais no começo do tratamento. As células parabasais predominaram durante todo o período observado em ambas as categorias, com tendência a apresentarem-se mais freqüentemente no segundo e terceiro períodos $(P<0,05)$, momento em que estava presente o implante de NOR, mimetizando a fase progesterônica do ciclo estral. REZENDE (2006) também descreveu a tendência de aumento das células parabasais durante o diestro de novilhas Nelore, ou seja, fase de dominância da P4 no ciclo estral.

As intermediárias jovens e as superficiais anucleadas foram mais freqüentemente observadas no primeiro e no quarto períodos $(P<0,05)$, ou seja, após as aplicações de BE. REZENDE (2006) também verificou o aumento destes tipos celulares durante o estro, momento este caracterizado pelo domínio estrogênico, com posterior diminuição das mesmas durante o desenvolvimento do ciclo estral. Resultados semelhantes foram encontrados por MIROUD e NOAKES (1990), que verificaram a predominância de células basais e intermediárias na fase do estro. Em relato anterior, feito por SANGER et al. (1958), constatou-se um pequeno número de células nesta fase, sendo a maioria do tipo superficial. Ainda segundo os mesmos autores, o estrógeno tem efeito direto no epitélio vaginal de fêmeas mamíferas, estimulando a estratificação do epitélio vaginal, sendo que, logo após a queda de suas concentrações séricas, segue-se uma extensa descamação das camadas superficiais. O número de células intermediárias velhas e superficiais nucleadas variou pouco durante o período observado. 
TABELA 1 - Porcentagem média $(\mu)$ e erro padrão (EP) de células vaginais basais (BAS); parabasais (PAR); intermediárias jovens (INJ); intermediárias velhas (INV); superficiais nucleadas (SNU) e superficiais anucleadas (SAN) nos diferentes períodos do protocolo hormonal em novilhas da raça Nelore, Caçu-GO, 2006

\section{Períodos}

\begin{tabular}{|c|c|c|c|c|}
\hline $\begin{array}{c}\text { Células } \\
(\%)\end{array}$ & $\begin{array}{c}\text { Período } 1 \\
\text { (D0 ao D2) }\end{array}$ & $\begin{array}{c}\text { Período } 2 \\
\text { (D3 ao D5) }\end{array}$ & $\begin{array}{c}\text { Período } 3 \\
\text { (D6 ao D8) }\end{array}$ & $\begin{array}{c}\text { Período } 4 \\
\text { (D9 ao D11) }\end{array}$ \\
\hline & $\mu \pm E P$ & $\mu \pm E P$ & $\mu \pm E P$ & $\mu \pm E P$ \\
\hline BAS & $5,40 \pm 1,20^{a}$ & $1,80 \pm 0,34^{b}$ & $2,07 \pm 0,37^{b}$ & $1,53 \pm 0,35^{b}$ \\
\hline PAR & $89,40 \pm 2,21^{a}$ & $96,47 \pm 0,84^{b}$ & $94,87 \pm 0,69^{b}$ & $93,93 \pm 1,40^{b}$ \\
\hline INJ & $2,13 \pm 0,61^{a}$ & $0,47 \pm 0,17^{b}$ & $1,80 \pm 0,57^{a, b}$ & $1,86 \pm 0,42^{a}$ \\
\hline INV & $0,07 \pm 0,07$ & $0,67 \pm 0,07$ & $0,13 \pm 0.91$ & $0,07 \pm 0,07$ \\
\hline SNU & $0,53 \pm 0,29$ & $0,67 \pm 0,07$ & $0,20 \pm 0,14$ & $0,47 \pm 0,34$ \\
\hline SAN & $2,47 \pm 1,09$ & $1,13 \pm 0,65$ & $0,93 \pm 0,25$ & $2,13 \pm 0,86$ \\
\hline
\end{tabular}

Médias seguidas de letras diferentes na mesma linha diferiram $(P<0,05)$ pelo teste " $t$ ".

Segundo MIROUD e NOAKES (1990), as alterações celulares no epitélio vaginal de bovinos não são consistentes e variam consideravelmente entre animais na mesma fase do ciclo reprodutivo, não sendo, portanto, indicadores do estágio do ciclo estral e/ou da ovulação, assim como relatado por RAPOSO et al. (1999) e ATIQUE NETTO (2003), que estudaram a citologia vaginal de cabras da raça Saanen e Alpina. Já para carnívoros e roedores o exame colpocitológico mostrou ser uma eficiente ferramenta na determinação da fase do ciclo estral (BOUCHARD et al., 1991; RAMOS et al., 2002). Provavelmente isso ocorra porque em outras espécies domésticas a ovulação ocorre durante o estro, pois o desenvolvimento do folículo inicia-se mais precocemente nestes animais, com efeito estrogênico na mucosa vaginal durante o estro e não após este, como parece acontecer com os bovinos (BROWN, 1944). 
TABELA 2 - Porcentagem média $(\mu)$ e erro padrão (EP) de células vaginais basais (BAS); parabasais (PAR); intermediárias jovens (INJ); intermediárias velhas (INV); superficiais nucleadas (SNU) e superficiais anucleadas (SAN) nos diferentes períodos do protocolo hormonal em vacas da raça Nelore, Caçu-GO, 2006

\begin{tabular}{|c|c|c|c|c|}
\hline \multirow{3}{*}{$\begin{array}{c}\text { Células } \\
(\%)\end{array}$} & \multicolumn{4}{|c|}{ Períodos } \\
\hline & $\begin{array}{l}\text { Período } 1 \\
\text { (D0 ao D2) }\end{array}$ & $\begin{array}{l}\text { Período } 2 \\
\text { (D3 ao D5) }\end{array}$ & $\begin{array}{l}\text { Período } 3 \\
\text { (D6 ao D8) }\end{array}$ & $\begin{array}{c}\text { Período } 4 \\
\text { (D9 ao D11) }\end{array}$ \\
\hline & 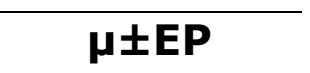 & $\mu \pm E P$ & 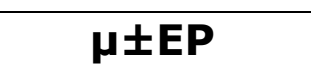 & $\mu \pm E P$ \\
\hline BAS & $5,58 \pm 1,13^{a}$ & $1,25 \pm 0,33^{b}$ & $1,42 \pm 0,34^{b}$ & $2,67 \pm 0,87^{b}$ \\
\hline PAR & $82,08 \pm 3,54^{a}$ & $94,67 \pm 1,11^{b}$ & $91,33 \pm 1,33^{b}$ & $86,17 \pm 2,77^{a, b}$ \\
\hline INJ & $4,92 \pm 1,92^{a}$ & $1,83 \pm 0,47^{b}$ & $4,67 \pm 0,93^{a, b}$ & $6,83 \pm 1,58^{a}$ \\
\hline INV & $1,00 \pm 0,30^{a}$ & $0,25 \pm 0,18^{b}$ & $0,50 \pm 0,34^{a, b}$ & $0,50 \pm 0,15^{a, b}$ \\
\hline SNU & $0,58 \pm 0,42$ & 0 & $0,33 \pm 0,26$ & $0,33 \pm 0,19$ \\
\hline SAN & $6,67 \pm 2,01^{a}$ & $2,0 \pm 0,67^{b}$ & $1,75 \pm 0,57^{b}$ & $3,67 \pm 1,59^{a, b}$ \\
\hline
\end{tabular}

Médias seguidas de letras diferentes na mesma linha diferiram $(P<0,05)$ pelo teste " $t$ ".

\section{CONCLUSÕES}

Portanto, conclui-se que citologia vaginal apontou, em novilhas e vacas Nelore, maior número de células basais, intermediárias jovens e superficiais anucleadas depois da aplicação de BE no início do protocolo. Nas duas categorias houve predominância de células parabasais durante a permanência do implante de NOR, portanto sob ação progesterônica. A citologia vaginal não forneceu elementos para determinação do momento da ovulação em fêmeas bovinas da raça Nelore submetidas à sincronização da ovulação. 
Ferraz, H.T., Oliveira Filho, B.D., Gambarini, M.L. et al. Efeito do protocolo de sincronização de ovulação com Norgestomet e Benzoato de estradiol sobre a citologia vaginal de novilhas e vacas Nelore. PUBVET, Londrina, V. 2, N. 47, Art\#454, Nov4, 2008.

\section{REFERÊNCIAS}

1 - ATIQUE NETTO, H. Acompanhamento ultra-sonográfico da involução uterina, citologia vaginal e níveis plasmáticos da progesterona e estrógeno durante o puerpério em cabras das raças Saanen e Alpina. Jaboticabal, 2003. 81f. Dissertação (Mestrado em Medicina Veterinária) - Faculdade de Ciências Agrárias e Veterinárias, Universidade Estadual Paulista - UNESP.

2 - BANKS, W. Histologia Veterinária Aplicada. 2.ed., São Paulo: Manole, 1991. p. 565588.

3 - BOUCHARD, G.F.; SOLORZANO, N.; CONCANNON, P.W.; YOUNGQUIST, R.S.; BIERSCHWAL, C.J. Determination of ovulation time in bitches based on teasing, vaginal cytology, and Elisa for progesterone. Theriogenology, Stoneham, v.35, n.3, p. 603-611, 1991.

4 - BROWN, P.C. Physiological and histological changes in the vagina of the cow during the estrus cycle. American Journal of Veterinary Research, Chicago, v.5, n.15, p. 99-112, 1944.

5 - GOMPEL, C.; KOSS, L.G. Citologia hormonal. In: GOMPEL, C.; KOSS, L.G. Citologia ginecológica e suas bases anatomo-clínicas. São Paulo: Manole, 1997, p. 49-60.

6 - HAMILTON, W.J.; HARRISON, R.J. Cyclical changes in the uterine mucosa and vagina of the goat. Journal of Anatomy, London, v.85, n.4, p. 316-326, 1951.

7 - KURADE, N.P.; JALNAPURKAR, B.V.; MANTRI, A.M. Exfoliative vaginal cytology and serum progesterone levels in normal and abnormal oestrus cycle of cow. Indian Journal of Animal Reproduction, Madras, v.1, n.14, p. 10-13, 1993.

8 - MARCONDES, N. Atlas de citopatologia ginecológica. Rio de Janeiro: Ateneu, 1975. 230 p.

9 - MIROUD, K.; NOAKES, D.E. Exfoliative vaginal cytology during the oestrous cycle of the cow, after ovariectomy, and after exogenous progesterone and oestradiol-17ß. British Veterinary Journal, London, v.5, n. 146, p. 387-397, 1990.

10 - MONTALBÁN, E.B. El Ciclo Endometrial. In: AYALA, M.J.; VILAPLANA, E.; ORTIZ, F.N.; FERNANDEZ, F.N. Citopatologia ginecológica. 2.ed. Barcelona: Editorial Científico Médica, 1985, p. 357-370.

11 - PAPANICOLAU, G.N. A general survey of the vaginal smear and its use in research and diagnosis. American Journal of Obstetrics and Gynecology, Saint Louis, v.51, n.3, p. $317,1946$.

12 - RAMOS, J.G.; VARAYOUD, J.; BOSQUIAZZO, V.L.; LUQUE, E.H.; MUÑOZ-DE-TORO, M. Cellular turnover in the rat uterine cervix and its relationship to estrogen and progesterone receptor dynamics. Biology of Reproduction, Champaign, v.67, n.3, p. 735-742, 2002.

13 - RAPOSO, R.S.; SILVA, L.D.M.; LÔBO, R.N.B.; FREITAS, V.J.F.; DIAS, F.E.F. Perfil citológico vaginal de cabras cíclicas da raça Saanen. Ciência Animal. Fortaleza, v.9, n.2, p.75-79, 1999.

14 - REZENDE, L.C. Perfil citológico vaginal e dinâmica folicular durante o ciclo estral em novilhas Nelore. Goiânia, 2006. 35f. Dissertação (Mestrado em Ciência Animal) - Escola de Veterinária, Universidade Federal de Goiás.

15 - SANGER, V.L.; ENGLE, P.H.; BELL, D.S. The vaginal cytology of the wave during the estrous cycle. American Journal of Veterinary Research, Chicago, v.19, n.3, p. 283-287, 1958.

16 - SAS - User's Guide: Statistics. 5.ed. Cary: SAS Institute, 2000, 1028p. 